\title{
Shame and Justice: Partners of Individuals on Sex Offender Registries Encourage Policy Reform
}

\author{
Kristan N. Russell ${ }^{a}$, Katie M. Snider ${ }^{b}$, William P. Evans ${ }^{b}$, and Shawn C. Marsh ${ }^{b}$

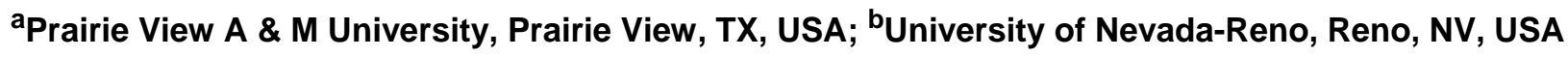

\begin{abstract}
Sex offense registration and notification (SORN) policies can contribute to stigma and negative consequences for partners of registered individuals. The present study utilized a self-report questionnaire to ask these partners what they would say to policymakers if given the opportunity. A thematic analysis of the responses revealed three themes which highlight the distinct issues related to registries, describe direct consequences experienced by the partners, and propose changes to existing policy. This study provides valuable insight into the experiences of a hard-to-reach population and can help generate critical discussion around the sweeping impacts SORN policies have on individuals they were not intended to reach. Implications for qualitative criminology and policy are discussed.
\end{abstract}

JQCJC "Qualitative Criminology," (2022)

Vol. 11, Iss. 1, 89-114

ARTICLE HISTORY

Received 7/22/2021

Accepted 8/30/2021

\section{KEYWORDS}

Sex offender, registry, policy

Since the 1990's, the United States has witnessed a proliferation of federal and statelevel sex offender registration and notification (SORN) policies. In brief, these policies aim to reduce sexual offending through incapacitative measures (e.g., residence restrictions) and deterrence measures (e.g., public registration and community notification) (Socia, 2012). SORN policies have developed through public demand for more punitive approaches to address sexual offending following several tragic and highly publicized sexual crimes against children (Kahn et al., 2017; Prescott, 2012; Robbers, 2009; Vasquez et al., 2008; Wright, 2008) and continue to receive tremendous public support (Proctor, et al., 2002). Unfortunately, these policies have been implemented with little evaluative evidence or regard for others who may be unintentionally impacted. This study aims to assess the collateral consequences experienced by partners of registered individuals by bringing their voices into the conversation on policy reform.

DOI: https://doi.org/10.21428/88de04a1.0eadc609

CONTACT Kristan N. Russell (knrussell@pvamu.edu), Prairie View A \& M University, Prairie View, TX, USA

(c) Southwest Criminal Justice Association 


\section{Literature Review}

Persons required to register on public sex offense registries experience salient forms of stigmatization (Burchfield, 2012; Burchfield \& Mingus, 2008; Cubellis et al., 2019; Evans \& Cubellis, 2014; Farkas \& Miller, 2007; Tewksbury, 2007; Zevitz \& Farkas, 2000). Partners and spouses of registered individuals also may experience courtesy stigma, which is stigma experienced by an individual resulting from their association with a "deviant" other (Goffman, 1963; Harris et al., 2011; Larson \& Lane, 2006; Pryor et al., 2012). Examples of courtesy stigma have been found for a variety of populations, including parents of prisoners (Gueta, 2018); family members of individuals who are HIVpositive (Lichtenstein et al., 2010), parents of teenagers who have ADHD (KoroLjungberg \& Bussing, 2009); and mothers of school shooters (Melendez et al., 2016); and thus, is not unique to those associated with individuals who have committed sex offenses. Research demonstrates that the negative consequences manifesting from courtesy stigma are often equivalent in severity to the consequences experienced by the primary stigmatized individual (Kulik et al., 2008; Larson \& Lane, 2006).

Partners of registered individuals are uniquely impacted by both SORN policies and consequent courtesy stigma, resulting in reductions of social support (Arditti, 2005; Jones \& Beck, 2005), overall well-being (Russell, 2020), and mental health (Levenson \& Tewksbury, 2009; Robbers, 2009). Individuals also may experience a sense of disenfranchised grief as they mourn the physical loss of their partner due to incarceration or a "psychosocial death" of the person they once knew, before the sex offender label was applied (Bailey, 2018). Further, SORN policies intended to manage and monitor the registered individual also may directly affect their partners. SORN policies restrict registered individuals in where they can live and travel, what types of events they can attend, and what types of technology/internet access they can have inside their homesall of which will affect the partner if they wish to cohabitate or travel with the registered individual. Registration also results in a decreased likelihood of accessing educational resources, obtaining and maintaining gainful employment, and achieving financial stability (Levenson \& Cotter, 2005; Prescott, 2012; Tewksbury, 2005; Tewksbury \& Lees, 2006). Registered individuals often fear harassment, judgment, and vandalism enacted by members of their community, and may experience these things directly (Farkas \& Miller, 2008; Tewksbury \& Lees, 2006). Again, all of these consequences also likely affect the lives of their partners.

Since their inception, SORN policies have been criticized for lack of effectiveness in decreasing sexual recidivism (Freeman, 2012; Letourneau et al., 2010; Socia, 2012; Zevitz, 2006), inconsistencies in data and tier classification (Robertiello \& Terry, 2007), substantial financial and resource costliness (Pittman \& Nguyen, 2011), and collateral 
"Qualitative Criminology"

consequences (e.g., difficulty obtaining a job, social ostracism, loss of housing) for registered individuals that can impede successful reintegration and rehabilitation (Levenson \& Cotter, 2005; Prescott, 2012; Tewksbury, 2005; Tewksbury \& Lees, 2006). The ongoing issues outlined here have generated the interest of researchers and advocates and have informed policy reform efforts. Reform efforts, however, have remained unsuccessful due to public and policymakers' strong and stigmatized beliefs surrounding this population.

Policy debates and evidence presented for reform tend to focus on the impact of policies on the registered individuals themselves. Importantly, the negative effects resulting from SORN policies may extend to individuals close to registered individuals, such as their children and partners (Levenson \& Tewksbury, 2009). It is important to consider those collaterally impacted yet largely left out of these policy discussions, to have an opportunity to voice their experiences and make suggestions for reform (Marsh et al., 2021). Partners are uniquely positioned to be able to provide support for registered individuals during their reintegration, a mechanism likely disrupted if they also are negatively impacted by SORN policies (Russell, 2020). Given their closeness to the registered individual and their desire to see them successfully reintegrated, partner perspectives and suggestions for policy reform are especially valuable.

\section{Current Study}

The current study sought to address these issues by examining open-ended survey responses of partners of registered individuals regarding their thoughts on current SORN policies. Our goal was to better understand how partners and spouses are affected by existing policies, to know what they would like policymakers to know about their experiences, and to gain insight into their perspectives regarding needed reforms and potential solutions.

\section{Method}

Data for this study derive from a larger, national online Qualtrics survey of partners of individuals required to register which focused on courtesy stigma (see Marsh et al., 2021; Russell, 2020). Respondents were recruited through strategic snowball sampling in 2018. To complete the sampling, we created a contact list of over 200 potential gatekeepers for dissemination of the survey link to potential respondents. The contact list included professional contacts, related organizations and advocacy groups, department of corrections, probation and parole services, treatment providers, housing and residency providers, and lawyers and attorneys. The survey link also was disseminated on social media (e.g., Twitter, Facebook, Reddit) and through discussion boards and online 
newsletters/blogs via relevant organizations (see Russell, 2020 for a more detailed overview of the sampling strategy and contact list). Once potential respondents clicked the survey link, they were screened to ensure they were 18 years of age or older, U.S. citizens, and currently or previously in a relationship with someone mandated to register on a public sex offense registry.

The present study examines an open-ended policy question from the larger survey; thus, the findings are based on the 221 respondents that completed this item. The majority of these respondents (204) identified as female and as white/Caucasian ( $n=188,85 \%)$. The respondents were an average of 44.49 years old (range $=20-82, S D=13.40$ ) and heterosexual ( $n=191,86 \%)$, though participants also identified as bisexual $(6.8 \%)$, gay or lesbian (4.5\%), or preferred to self-describe their orientation (2.3\%).

Current and former partners of registered individuals from forty U.S. states and the District of Columbia responded to the survey. The most represented states for participants who answered the question of interest for this study were Texas, California, and Illinois. Income levels for the participants in this sample were captured categorically, and the distribution was multimodal. Fourteen percent of respondents placed their annual income between $\$ 20,001$ and $\$ 30,000$, and an equal number of respondents placed their annual income between $\$ 40,001$ and $\$ 50,000$. Table 1 presents the overall demographic characteristics of respondents who completed this open-ended policy question.

Respondents were asked the open-ended question; "In recent years, researchers have been trying to better understand how sex offender registration and notification policies impact the families and partners of registrants. If you had the opportunity to talk to policymakers who were considering how to reform or improve existing policies, what would you say?" An essay-style text box encouraged respondents to provide as much detail as possible. Responses from this item are used in the primary analysis of this study.

A thematic analysis process developed by Braun and Clark (2006) allowed for a flexible approach to identifying, analyzing, and reporting themes present in the current data. This thematic analysis was conducted using an essentialist method, which aims to report the experiences, meanings, and reality of the respondents rather than a constructivist method which would aim to examine the ways in which those factors are the effect of societal discourse (Braun \& Clark, 2006). Further, the analysis was conducted using an inductive approach (Boyatzis, 1998; Braun \& Clark, 2006) which allows responses to be coded from a "bottom up" strategy where codes emerge from the data, rather than trying to code the data based upon preconceived coding schemes. 
"Qualitative Criminology"

Table 1: Respondent Demographics

\begin{tabular}{|c|c|c|c|c|c|}
\hline Variable & $\mathrm{n}$ & $\begin{array}{r}\text { Percent/ } \\
\text { Mean } \\
\text { (Range) }\end{array}$ & Variable & $\mathrm{n}$ & $\begin{array}{r}\text { Percent/ } \\
\text { Mean } \\
\text { (Range) }\end{array}$ \\
\hline Age (years) $X z$ & 219 & $44.59(20-82)$ & Education* & & \\
\hline Gender & & & Some high school & 3 & 1.36 \\
\hline Male & 15 & 6.79 & HS diploma/GED & 48 & 21.72 \\
\hline Female & 204 & 92.31 & Associates/2-year degree & 57 & 25.79 \\
\hline Self-describe & 2 & .90 & Bachelors/4-year degree & 65 & 29.41 \\
\hline Sexual Orientation & & & Master's degree & 45 & 20.36 \\
\hline Heterosexual & 191 & 86.43 & Doctoral degree & 3 & 1.36 \\
\hline Bisexual & 15 & 6.79 & Income & & \\
\hline Gay/lesbian & 10 & 4.52 & 10,000 or less & 8 & 3.62 \\
\hline Self-describe & 5 & 2.26 & $10,001-20,000$ & 16 & 7.24 \\
\hline Race & & & $20,001-30,000$ & 30 & 13.57 \\
\hline White/Caucasian & 188 & 85.07 & $30,001-40,000$ & 51 & 23.08 \\
\hline African-American/Black & 6 & 2.71 & $40,001-50,000$ & 30 & 13.57 \\
\hline Hispanic/Latino & 11 & 4.98 & $50,001-60,000$ & 24 & 10.86 \\
\hline Asian & 9 & 4.07 & $60,001-70,000$ & 19 & 8.60 \\
\hline American Indian/Alaskan Native & 1 & .45 & $70,001-80,000$ & 13 & 5.88 \\
\hline Biracial & 1 & .45 & $80,001-90,000$ & 11 & 4.98 \\
\hline Multiracial & 3 & 1.36 & $90,001-100,000$ & 17 & 7.69 \\
\hline Other & 2 & .90 & 100,001 or more & 25 & 11.31 \\
\hline Parent (Yes) & 151 & 68.33 & & & \\
\hline \multicolumn{6}{|l|}{ Political Affiliation* } \\
\hline Republican & 48 & 21.72 & & & \\
\hline Democrat & 73 & 33.03 & & & \\
\hline Independent & 63 & 28.51 & & & \\
\hline Other (please specify) & 33 & 14.93 & & & \\
\hline
\end{tabular}

* Response rates for political affiliation (98.2\%) and education level (100\%) were significantly higher for the subset of respondents who answered the open-ended policy question than they were for the overall survey sample $(77.4 \%$ and $79.5 \%)$ respectively.

Following the steps outlined by Braun and Clark (2006), the first author first reviewed responses, making note of topic areas for potential coding. Following this, an initial coding scheme was developed, and coding of all data was completed in a systematic fashion by the first and second authors. Interrater reliability was assessed by randomly assigning both coders to complete a subset of responses (10\%). A pooled kappa of 0.71 was observed, suggesting moderate agreement (McHugh, 2012) between the coders. Inconsistencies were examined which revealed that for most of the crosscoded sections, the coders agreed on the primary codes and the few discrepancies were primarily related to the quantity of subcodes applied. To further ensure all codes were interpreted and coded consistently, the coders discussed and addressed discrepancies in the coding, and reviewed and refined code definitions. Next, the authors searched for and reviewed potential themes. Once it was determined that the themes aligned with the 
coded extracts and datasets, the themes were further analyzed, and definitions generated. The notable themes identified in this study are detailed below.

\section{Findings}

Of the 221 responses, 213 were included in the analysis. Eight responses were dropped and were unable to be coded due to irrelevancy (e.g., "see above," "N/A"). From the detailed thematic analysis of the remaining 213 responses, three primary themes were identified: (a) registry issues, (b) policy direct consequences, and (c) proposed policy changes. Within each, a number of subthemes also were generated. Each theme is discussed below, followed by their associated subthemes. As all survey responses were anonymous, and respondent IDs were assigned to identify respondent quotes in the analysis. Quotations from respondents are presented verbatim in an effort to retain the respondents' original intended meaning and thus, may contain grammatical or punctuation errors. All the themes, subthemes, and code counts are highlighted in Table 2.

Table 2: Theme and Subtheme Code Presence Counts (by Participant)

\begin{tabular}{lrlr}
\hline Theme & Participants & Theme & Participants \\
\hline Registry issues & $\mathbf{1 3 3}$ & Proposed changes & $\mathbf{1 0 7}$ \\
One size does not fit all & 25 & Limit to law enforcement & 30 \\
Ineffectiveness & 44 & Consider context & 23 \\
Further punishment & 27 & Proposed removal & 22 \\
Low re-offense rates & 12 & Length requirements & 21 \\
Direct consequences & $\mathbf{9 8}$ & Use existing research & 19 \\
Stigma & 30 & Second chances & 16 \\
Housing & 30 & Worst only & 14 \\
Parent involvement & 18 & & \\
Isolation & 17 & & \\
\hline
\end{tabular}

\section{Primary Theme 1: Registry Issues}

When asked what they would say to policymakers, $133(62.4 \%)$ of the respondents commented on existing issues related to SORN policies. These individuals referred to the failures of existing registries by highlighting the ways in which they are ineffective or do not produce the intended results. Within this theme, four subthemes were identified; (a) one size does not fit all, (b) ineffectiveness, (c) further punishment, and (d) low re-offense rates (see Figure 1). Each sub-theme is outlined below with definitions and example excerpts from the responses. 
Figure 1: Overview of Primary Theme 1 (Registry Issues)

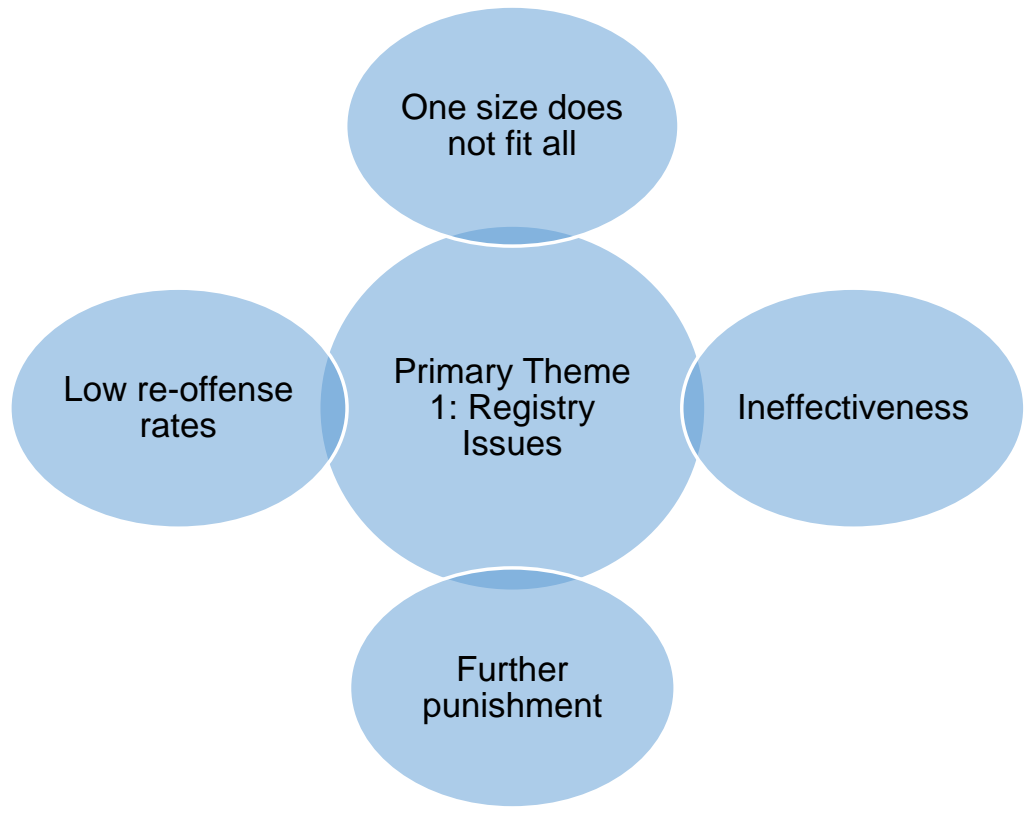

\section{One Size Does Not Fit All}

Twenty-five respondents discussed the issue of broad sex offense policies being applied to all registered individuals classified under that umbrella, despite this group being heterogenous and in need of individualized approaches. In this subtheme, many respondents specifically state that this "one size fits all" approach is not effective and that it is a primary issue with registries. Respondents frequently cited a "lumping together" of all registered individuals with very diverse criminal offending histories (e.g., teenager adjudicated for a first-time offense with a serial child molester) into a registry and tiersystem that does not properly delineate their differing characteristics and risk levels. One respondent talked about how this one size fits all approach is used with this diverse population using examples.

The registry is a "one-size-fits-all" punishment that is applied to a wide array of offenses-from violent sexual attacks to teenage sexting, and is geared for the more gruesome end of the offense spectrum (Respondent \#7) 
Another alluded to the nature of registries using a one size fits all approach to labeling registered individuals and argued that they should be more carefully considered with an individualized approach based on case-related factors.

Not all sexual offenders should be judged as quote unquote baby rapers. Due to circumstances each case should be judged on a case by case basis. Some offenders are high school sweethearts Romeo and Juliet laws should be looked at before sticking a person with any registry requirements. (Respondent \#106)

Ineffectiveness

Forty-four respondents highlighted the ineffectiveness of registries. In their responses they emphasized how the goals of registries (i.e., increase in public safety, deterrence of sexual crimes) have not been met. Others highlighted issues that make the registries ineffective such as their potential to do more harm to the registered individual and their families, rather than helping with successful reentry. Some respondents underscored that the registries are built upon the misperception of "stranger danger" and sexual crimes, when the majority of sexual offenses are perpetrated by family members or acquaintances.

The registry and public notification systems have not been found to effect recidivism. The registry is not making anyone safer, nor is it preventing anyone from re-offending. (Respondent \#94)

Another respondent further elaborated upon the ways in which this ineffective system can be counterproductive to its intended goals. This respondent also makes suggestions for evidence-based approaches to improve effectiveness.

I would STRONGLY advise them to do away with registration. It does little or nothing to make the public safer and makes it extremely difficult for former sex offenders to re-integrate into society as productive citizens. It isolates and oppresses them to the point that any kind of life success is practically impossible and ultimately contributes to another criminal offense, sexual in nature or otherwise. If registry repeal is not done, at least do away with the Adam Walsh Act and classify offenders under a tier system that is scientifically based so the public can determine who is actually a severe threat from those who are little or no threat. (Respondent \#65) 


\section{Further Punishment}

Twenty-seven respondents discussed the way in which registries are used as another means of punishment, rather than a policy to aid in improving public safety. A number of these respondents specifically refer to the fact that their partners have already served a full prison sentence but that the registry allows for continued, and sometimes a lifetime, punishment. This is a system unique to sexual offenses, and as some respondents point out, is a punitive measure we do not even require of murderers. One respondent highlighted these issues by describing the ways in which these registries punish the registered individuals and their families through public shaming.

The registry is most definitely punishment. It hurts families because they cannot get decent jobs or housing. It is used to humiliate and shame the family and does very little to protect the community. People are placed on the registry as a political gain, so it can be said look at how many people we caught. No other group of people who have committed crimes have to register. The registry is one step away from the Scarlett's letter. (Respondent \#177)

Another emphasized the way in which those convicted of sexual offenses are continuously punished through registry policies which present barriers for successful reintegration.

System, as it is today, is broken. He is oppressed by a system that continues to judge him suspiciously for crime he committed when he was a completely different person. On a daily based he is forced to navigate life knowing he is despised by the media and at times people around him. The people charged with helping him reintegrate back into society (PO) have denied him opportunity for achievement and actively place barriers in his path. My partner has paid for his crime a million times over. How much longer does he have to pay? (Respondent \#149)

\section{Low Re-Offense Rates}

Furthermore, twelve respondents describe and cite low re-offense rate statistics associated with sexual offending. These respondents highlight a clear contradiction that the goal of registries is to reduce offending for a group of individuals who already have very low re-offending rates. As these responses highlight, it is unsurprising that registries have failed to lower re-offense rates. For example, one respondent underscores this contradiction by stating that: 
The laws that are created do not prevent an offense from happening since the registration every year grows in numbers and it is time to reevaluate that process since sexual offenses in many cases have the lowest recidivism rate. (Respondent 168)

Another questions the purpose of registries if these individuals are already unlikely to re-offend.

Most of the offenders on the registry never re-offend in this manner again so what is it doing except pointing fingers at these people and their families and causing them to not be a credible, contributing member of society. (Respondent \#192)

\section{Primary Theme 2: Direct Consequences}

In total, $98(46.0 \%)$ of the respondents wrote about the direct consequences they and their families experience as a result of their partner's sex offense registration. These individuals discussed a variety of consequences including how they are perceived, how policies disrupt their lives, and how they are impacted personally. Within this theme, four subthemes were identified; (a) stigma, (b) housing, (c) parent involvement, and (d) isolation (see Figure 2). Each sub-theme is outlined below with definitions and example excerpts from the responses.

Figure 2: Overview of Primary Theme 2 (Direct Consequences)

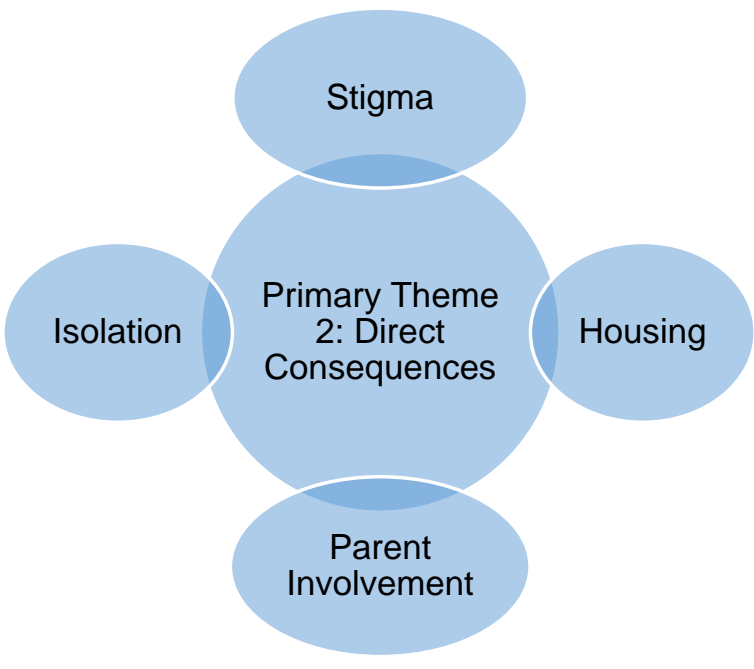


Stigma

Thirty respondents reported experiencing stigma as a direct consequence of their partner's registration status. These respondents discuss the ways in which their partner, themselves, and their children all experience stigmatization due to the registry. Many of these individuals refer to feeling humiliated or embarrassed, publicly shamed, and as having a "scarlet letter" attached to them. Respondents also mention feeling fearful that they will be judged or experience harassment due to their stigmatized status. One respondent talked about how this punitive approach publicly shames the registered individual and their partner.

If a person does a crime they should be punished for it but the registry has become a form of public shaming and a public hit list. It feels almost as if your loved one is wearing a form of a modern-day scarlet letter and others believe you condone sex crimes so they shun you as well. (Respondent \#182)

Additionally, another discussed the ways in which the stigmatizing effects extend beyond the registered individual to also affect the families.

Please take in consideration of the families and the shame, embarrassment and cruelty people can have towards the very innocent people. We are victims too. (Respondent 121)

\section{Housing}

Thirty respondents described housing concerns resulting from their partner's status on a public registry. Many of these responses centered around the effects of housing restrictions associated with residence policies. Respondents point out that when these restrictions require the registered individual to move, their families must often move as well. Several report that it is difficult to find landlords willing to rent to someone on the registry. They also indicate that finding and securing housing within strict restrictions can be difficult and there is always the fear that they will have to move as a result of future changes to the neighborhood (e.g., a park is built close by). Others describe their challenges with housing by discussing the effects of losing income that maintains their stable housing and fearing, or experiencing, evictions and homelessness as a result. For example, one respondent highlighted that these policies contribute to challenges of finding somewhere to live that is within restrictions and affordable.

There are so many different kinds of sex offenders, and each one has a personal history. To handicap someone by making them register for years (or the rest of 
their lives) consigns that person to a life of struggling to find a place to live, a job, and a way to make a living. If you are going to release a sex offender into the community, you have to allow them a way to support themselves. Do you really want them living in a tent in the woods (which is what one parole officer told my husband he would have to do if he couldn't find affordable housing)? If not, don't make it impossible for sex offenders to find a job or a place to live. (Respondent 187)

Another respondent referred to the fact that residence restrictions are essentially applied to the entire family unit and make their case for why these restrictions should not be used.

Think about the families because I would say a lot of registrants have families and in all honesty not just the registrant is "on the registry" but the whole family is limited because of these rules. The distance requirements are horrid and limit where families can live. Its not fair to my kids that their dad can not come to their sports events because they are in public parks. They are trying to make rules for that one, scary bad, person and have no idea that the majority of the people on the registry will not do anything again and are not bad, scary people. If they want to keep a list ok, but all the limits, restrictions and bans simply because your name is on a list have got to stop. (Respondent \#195)

\section{Parent Involvement}

Eighteen respondents reported that one of the consequences of sex offenses policies is that the registered individual is unable to be involved as a parent. Oftentimes, this comes in their inability to engage in typical supportive parenting activities such as attending school functions and sport or group events. They emphasize the ways in which this creates a barrier for the registered individual to fulfill their parenting duties and live up to their full parenting potential, as they are barred from coaching their child's teams, traveling or taking vacations with them, and visiting their children in hospitals. Further, they highlight how it is the children who are the victims and most affected by such policies, as they are unable to experience important bonding moments with their parent. One respondent elaborates upon the ways in which sex offense policies create unique challenges for parents on the registry (i.e., not being able to take kids out for trick or treating or Halloween events), of which a consequence is that the child's development may be negatively affected.

Now they are no longer able to take their children out making the children feel isolated and grow up as dysfunctional. This is creating new issues and new 
problems that will indeed cost more money to taxpayers. Oh, not to mention a lot of parents take their children to church Halloween parties in which a SO cannot go to church. Two solutions I can think of. Let the SO's rent a ankle monitor for the evening or allow them to have a chaperone for this evening if you still feel they are a threat. Public or family functions and vacations-All of these are things that bring a family together, builds good social skills, ups the self-esteem, teaches children, builds a sense of a strong family unit and community. These are important with everyone but truly important to growing minds (children). (Respondent \#1)

Another describes the ways in which these restrictions can make it difficult for parents on the registry to establish healthy relationships with their children.

Keeping registered sex offenders from attending their children (or stepchildren's) school or sporting events hurts EVERYONE involved. Even if the wives have to be an escort. We could do that. These are causing more problems in children because they're keeping fathers away from having a healthy relationship with their children. (Respondent \#96)

Isolation

Last, another important consequence mentioned by seventeen respondents was the experience of isolation. Many of these individuals report that sex offense policies can contribute to isolation of the registered individual, their partner, and their family members. It appears that this isolation can be externally created (e.g., individuals do not want to come around the registered individual and those associated with them) or internally created (e.g., the registered individual or their family members may isolate out of fear of being judged or harassed). Additionally, respondents refer to both physical and psychological isolation. One respondent describes the way in which the isolating effects of registration policies may extend to their children.

My biggest fear as a mother is that society will isolate my child for the poor choices his father has made. (Respondent \#132)

Another concisely states their view that registries are isolating and creates barriers for successful rehabilitation.

Your policies are actually isolating offenders and giving them less resources to help themselves and reform. (Respondent \#213) 
Primary Theme 3: Proposed Changes

In total, 107 (50.2\%) of the respondents indicated that current policies should be changed. These responses detail a variety of ways in which they feel policies should be changed to better manage this population effectively within the community. Within this theme, seven subthemes were identified; (a) limit to law enforcement, (b) consider context, (c) proposed removal, (d) length requirements, (e) use existing research, (f) second chances, and (g) worst only (see Figure 3 ). Each sub-theme is outlined below with definitions and example excerpts from the responses.

Figure 3: Overview of Primary Theme 3 (Proposed Changes)

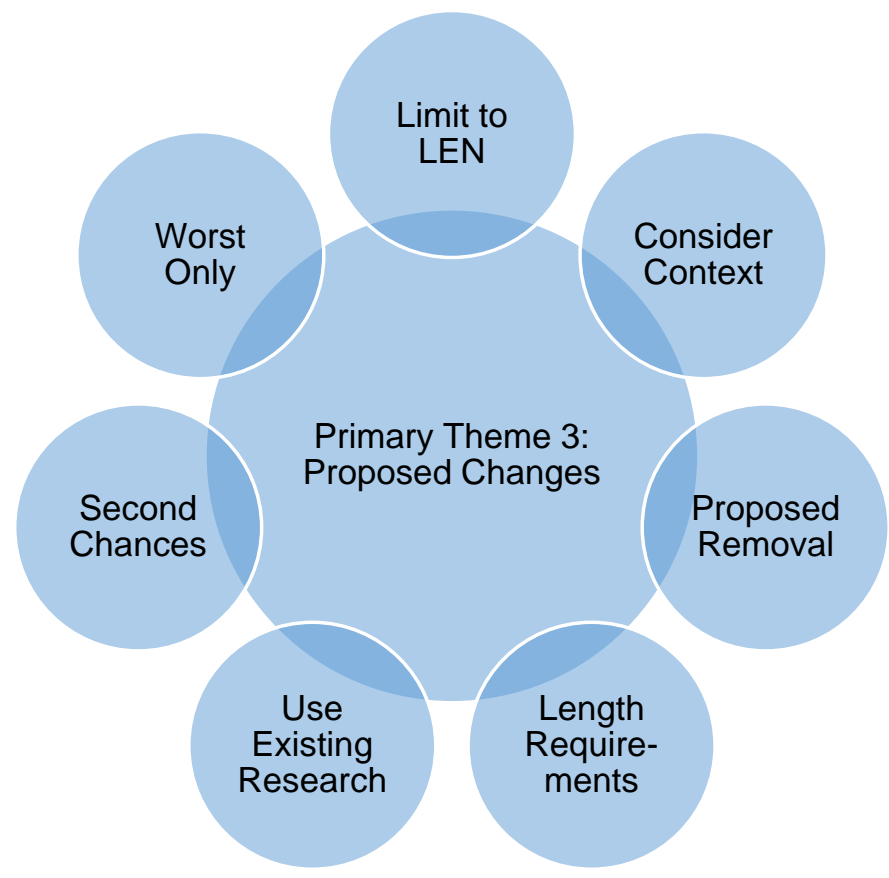

Limit to Law Enforcement (LEN)

Thirty respondents suggested that the registry should be limited to law enforcement only. Many of these individuals state that there is no need for public access to the registered individual's information and that limiting the information to only those who need it (e.g., police, probation officers), certain consequences such as stigma and harassment could be alleviated. One respondent pointed out a lack of evidence supporting the effectiveness 
of a public registry and suggests that the list should only be accessible by law enforcement professionals who require its use.

Remove the requirements to have those convicted of sex crimes to registry public. It a waste of resources, there's no evidence to prove that it keeps anyone safer. If any type of list should be kept it should be only for trained investigation purposes not for uneducated public. (Respondent \#137)

Additionally, another suggests a law enforcement-only registry by citing the ways in which public registries are problematic.

Make a police-only registry and require only sexually violent predators or repeat offenders be on it. It's an ex post facto punishment and does more harm than good. It's not a deterrent and instead of making communities safer it puts the offender and their family at risk of retaliation. (Respondent \#95)

\section{Consider Context}

Twenty-three respondents suggested that the registration system take context of each individual's situation and crime into consideration when determining who will be registered and for how long. These individuals encourage refraining from applying harsh registration requirements (e.g., lifetime registration) broadly to a diverse population of individuals. For example, one highlights that registration tiers should better distinguish between the contextual factors of the offense (e.g., one time only vs. repeat).

There needs to be a method of addressing cases on an individual basis, rather than an uncompromising categorization that fails to differentiate between a teenager that commits one offense and a serial rapist when it comes to punishment. (Respondent \#70)

Many of these respondents, such as the one below, simply state that these situations should be judged on an individualized basis.

Due to circumstances each case should be judged on a case by case basis. (Respondent \#106)

\section{Proposed Removal}

Twenty-two respondents recommended that the registry be removed altogether rather than being reformed. Many of the respondents who argue that the registry should be 
abolished propose using the funds for more effective resources. Others discuss that this removal would make society safer since registered individuals would have a greater chance of rehabilitating and successfully reentering society. One outlined why they believe registries should be removed and highlights that law enforcement can still access these records, as can potential employers.

Get rid of the registration. Law enforcement has access to records with or without a registration. Employers have the ability to complete background checks where needed. Anyone who thinks they can rely solely on a list of people who have been convicted is enjoying a false security. You should always be alert to inappropriate behavior. (Respondent \#37)

Another provided examples of ways the money could be reallocated to more effective programs.

Get rid of the registry and put the money to education, mental health initiatives, police training and other places that would actually make a difference. (Respondent \#124)

\section{Length Requirements}

Twenty-one respondents mention length requirements as a point of policy reform. More specifically, these respondents often argue against lengthy and lifetime registration requirements that are not proportionate to the severity or quantity of offending. Moreover, many of these individuals argue for some sort of review system that would allow for registration lengths to be reduced or a way to be removed from the registry altogether should they deserve it (e.g., successfully rehabilitated). For example, one respondent argues that lifetime registration can make the registered individual feel hopeless and removes their motivation to reform.

Once off probation there should NOT be any registry. Lifetime registry is unrealistic. It is like saying to a kid you are grounded forever! There is nothing to look forward to, no goal, no light at the end of the dark tunnel. You take away all hope of a normal life. Yet you want to reform them, but you give them nothing to gain. "A man who has nothing, loses nothing" I heard this said to me once by a felon. In their eyes it doesn't matter if he offends again because his life isn't worth shit any way. His words not mine!!!! (Respondent \#1) 
"Qualitative Criminology"

Another highlighted that registries punish registered individuals for lengthy periods of time and that this continued punishment post-incarceration is unique to sexual offending.

There needs to be clarification on the registry laws. There should be a way that people can get off the registry and not 10 to 20 years later. Most employment back grounds go back 7 years. There needs to be reformation on the state level. My partner was required to register for life because the judge felt it was deemed necessary not because of a rule or statute. Having to register feels like life is over. Even felons have a chance to get their life back after some time has passed. (Respondent \#191)

\section{Use Existing Research}

Nineteen respondents urged policymakers to use research findings and evidence to inform policy reform. Many of these individuals describe existing research findings (e.g., low recidivism rates) that tend to contradict public perceptions. Further, they point out research that indicates registries are ineffective. For example, one respondent describes the research that suggests most perpetrators of sexual offenses are familial or acquaintances and that registries are not adequately addressing these cases.

Look. At. The. Data. It is right there-screaming in your face. 95\% of sex offenses are committed by someone who it is their first offense (not prevented by the registry). $90 \%$ of all child sex abuse victims are related and/or know the perpetrator (not prevented by the registry). Sex offenses have the second lowest recidivism rate with the only lower one being for murder. The registry and public notification systems have not been found to effect recidivism. The registry is not making anyone safer, nor is it preventing anyone from re-offending. (Respondent \#94)

Another suggests policymakers consider research findings rather than allowing emotions to drive policy decisions.

I ask them to use scientific data to make policy and not to continue on a path where rules and laws are made on irrational emotions. (Respondent \#42)

\section{Second Chances}

In addition, sixteen respondents encourage policymakers to consider the importance of second chances. More specifically, these respondents refer to the need to allow registered individuals to pay for their crime through incarceration and punishment and 
then be given the opportunity to be a successful member of society. For example, one respondent describes making a one-time mistake at a young age as a reason for considering second chances.

People should be given second chances. Especially when they are young and make mistakes. Imagine being young and making a mistake (that didn't hurt anyone) and having to pay for it the rest of your life. (Respondent \#116)

Another concisely states that registered individuals should have a chance to successfully reintegrate after serving their sentence.

As for the registrants themselves everyone who is convicted of a crime should have a chance to go to serve their sentence and have a second chance to start over again and integrate into society. (Respondent \#129)

\section{Worst Only}

Fourteen respondents urged policymakers to consider reserving the use of registration for the worst offenses only. For example, they suggest that registration should be reserved for those who commit repeated heinous or violent sexual crimes. They suggest that those who commit less severe crimes (e.g., statutory rape in a scenario where two teenagers were engaged in a consensual relationship) should not be required to register. One respondent described the need to reserve the registry for the worst offenses only and described issues with the current way the policy is applied.

That the lifetime registration is overused and needs to be used for the worst crimes an offender can commit. Too many people are on the registry and there is no discernment between truly evil monsters who did absolutely heinous things to someone who made a mistake such as Romeo and Juliet laws. People should also have an opportunity to get off the registry. (Respondent \#155)

Another suggests that total removal is ideal but, if it is not an option then policymakers should reserve the registry for the highest risk individuals only.

Remove them. They are not serving any real purpose. If you must have them only have the worst offenders those high risk and the ones most likely to reoffend. They SHOULD NOT be made public. (Respondent \#139) 


\section{Discussion}

Existing data suggest that individuals who have committed sexual offenses have low rates of recidivism (Bureau of Justice Statistics,2002; Sample \& Bray, 2006). Given this, in combination with the lack of evidence for the effectiveness of SORN policies (Zgoba \& Mitchell, 2021), the consequences that they and their partners experience may be substantially disproportionate to the original offense and the risk they pose to the community. No person wants to be judged solely by the worst mistake they ever made. Yet for partners of registered individuals, who are often judged by the worst mistake their partner ever made, the subsequently experienced collateral consequences can be incredibly harmful.

Partners of registered individuals offered insight into how SORN policies have negatively affected themselves personally, as well as how their families have been affected. Participants in this study were especially concerned with the blanket labeling that is accomplished by SORN policies (one-size-fits-all treatment of sexual offending). Though most state registries include some details regarding the type of offense for which a person was convicted, the participants in this study consistently pointed out that the consequences of being listed on the registry are similar, regardless of the offense type. Respondents also pointed out that registries serve as further punishment for individuals who have committed a sexual offense (both socially and financially), while they fail to protect the community from predatory sexual behavior.

Registered individuals experience high levels of social stigma, and that stigma often extends to their close associates, including partners and children. In addition to stigma, participants revealed that they experienced direct consequences as a result of their relationships with registered individuals. Housing limitations that are placed on registered individuals are de facto placed on their entire family, should the family decide to cohabitate. Similarly, restrictions regarding proximity to schools and other places children frequent (regardless of whether the sexual offense involved children), can affect partners by placing the responsibility for any and all child-related activities on them, because their co-parent cannot legally engage in these activities, or be physically present where the activities occur. Further, internet restrictions within the home affect the entire family, a consequence likely exacerbated during the COVID-19 pandemic when many were required to work and attend school remotely. Theoretically, families could choose to live apart so that the children and non-registered partner could be closer to amenities like parks and schools and better able to access internet within their homes. Many respondents, however, discussed the negative financial and employment consequences of their partners' registration status, which would make affording separate residences an unlikely solution. 
Participants in this study discussed the social and emotional consequences that their children have experienced as a result of their partners' registration. In addition to missing their registered parent at important child-centric activities, children also can experience bullying and social isolation when their peers learn of their parent's registration status. Partners, too, may experience social isolation as a direct result of their association with the registered individual. They may face social rejection or have to choose between their relationship with the registered individual and other important relationships, if and when contacts in their social network learn of their partner's offense history.

Participants suggested a number of meaningful policy changes that they feel would reduce the added burden on families, and the lifelong punishment of low-risk individuals. Offenses that require registration for sexual offenses can vary widely, from public urination to statutory rape, to child sexual assault. The overall risk that registered individuals pose to society should be reflected in their registration level, but tier levels tend to be inconsistent and may not be the best descriptor for risk. It is likely that, because the registered individuals themselves are treated as a "one-size-fits-all" group, their partners may encounter similar courtesy stigma stressors they experience, and the consequences they and their families endure. Thus, participants in this study recommended changes to the registry to better differentiate registered individuals based on their offense type and actual risk level. Participants also recommended a host of other changes, like only requiring registration for the "worst" offenses, creating length requirements or abolishing lifetime registration, limiting registry access to law enforcement, or abolishing the registry altogether. Finally, a number of participants said they would encourage policymakers to employ existing research on sexual offending, recidivism, and the registry to make more informed policy decisions.

\section{Limitations}

The limitations of this study should be considered when interpreting the findings. The current study used a purposive snowball sampling approach to reach participants for a self-report survey. Thus, response rates are unknown, so the representativeness of the sample and generalizability of the findings are difficult to assess. The open-ended item examined in this study was part of a broader questionnaire. Participants may have been fatigued from answering other items which may have subsequently affected how much detail they provided in their responses. Response detail may have also been limited by the medium through which the individual completed the survey (e.g., on computer with keyboard or on a mobile device). It is possible that the burden of typing responses on a mobile device limited the amount of information and detail provided. Future research should use comprehensive and robust qualitative methodologies (e.g., in-depth 
interviewing) to assess the impact of stigma and SORN policies on registered individuals, their partners, and family members. Additionally, longitudinal, partner dyadic, and crosscultural studies are needed to fully understand the impact of SORN policies on registered individuals and their ripple effects on partners and family members, as well as the possibility of intergenerational effects.

\section{Implications}

Current findings have implications for qualitative criminology research. Criminology scholars are often challenged with accessing, developing rapport with, and getting data from highly stigmatized populations. Given their ability to protect anonymity, online surveys can be an effective tool in accessing hard-to-reach populations. Further, using open-ended surveys items is an accessible first step for gathering insightful and detailed qualitative data before diving into more in-depth approaches (e.g., in-depth interviewing) that do not provide the respondents anonymity from the researchers (Marsh et al., 2021; Russell, 2020). This allows the researchers to demonstrate their intentions with this line of research, building rapport with respondents, resulting in a network of individuals who indicated their interest in being contacted for participation in more in-depth follow-up studies (Marsh et al., 2021; Russell, 2020). It also is worth noting that embedding openended items within a survey allows for further contextualization of the quantitative responses and theoretical models.

This study also has implications for policy. Policy reform efforts are underway but may be unsuccessful as stakeholders often hold stigmatized views of registered individuals and have been resistant to policy change. In fact, recent legislation such as the Military Sex Offender Reporting Act (2015) and the International Megan's Law (2016) expanded current SORN policies rather than scaled them back. The impact of these SORN policies on innocent partners and family members is an important consideration that has been largely excluded from this discussion. Not only does this study shed light on the severity and reach of the collateral consequences stemming from SORN policies, but it also provides a platform for these individuals to share their unique perspective on policy reform strategies. Further, the responses highlight the need for policymakers and advocates to consider opportunities for public education regarding registries. For the families of registered individuals (and the registered individuals themselves), there are widespread public misconceptions about the types of offenses and the prevalence of different offense types, for people on the registry. Public education programs, could help to alleviate some of the stigma faced by registered individuals and their families.

SORN policies and their effect on registered individuals and those associated with them continue to be an important avenue for future research given the high costs to 
society of maintaining these systems. Understanding the full extent of collateral consequences experienced by registered individuals and their families allows for more comprehensive conversations around policy reform. Further, as yielded in the current study, discussion with those who are affected by existing policies can generate unique and evidence-based ideas for alternative approaches that may be more effective in aiding successful reintegration and increased community safety.

\section{References}

Arditti, J. A. (2005). Families and incarceration: An ecological approach. Families in Society, 86(2), 251-260.

Boyatzis, R. E. (1998). Transforming qualitative information: Thematic analysis and code development. Sage Publications.

Braun, V., \& Clarke, V. (2006). Using thematic analysis in psychology. Qualitative Research in Psychology, 3(2), 77-101.

Bureau of Justice Statistics. (2003). Recidivism of sex offenders released from prison in 1994. Washington, DC: U.S. Department of Justice.

Cubellis, M. A., Evans, D. N., \& Fera, A. G. (2019). Sex offender stigma: An exploration of vigilantism against sex offenders. Deviant Behavior, 40(2), 225-239.

Evans, D., \& Cubellis, M. (2015). Coping with stigma: How registered sex offenders manage their public identities. American Journal of Criminal Justice, 40(3), 593-619.

Farkas, M. A., \& Miller, G. (2007). Reentry and reintegration: Challenges faced by the families of convicted in a psychiatric setting. Social Problems, 23(3), 305-311.

Freeman, N. J. (2012). The public safety impact of community notification laws: Rearrest of convicted sex offenders. Crime and Delinquency, 58(4), 539-564.

Goffman, E. (1963). Stigma: Notes on the Management of Spoiled Identity. Englewood Cliffs, NJ: Prentice-Hall.

Gueta, K. (2018). The experience of prisoners' parents: A meta-synthesis of qualitative studies. Family Process, 57(3), 767-782. 
"Qualitative Criminology"

Harris, A., Evans, H., \& Beckett, K. (2011). Courtesy stigma and monetary sanctions: Toward a socio-cultural theory of punishment. American Sociological Review, 76(2), 234264.

Jones, S. J., \& Beck, E. (2006). Disenfranchised grief and nonfinite loss as experienced by the families of death row inmates. OMEGA-Journal of Death and Dying, 54(4), 281299.

Kahn, R. E., Ambroziak, G., Hanson, R. K., \& Thornton, D. (2017). Release from the sex offender label. Archives of Sexual Behavior, 46(4), 861-864.

Koro-Ljungberg, M., \& Bussing, R. (2009). The management of courtesy stigma in the lives of families with teenagers with ADHD. Journal of Family Issues, 30(9), 1175-1200.

Kulik, C. T., Bainbridge, H. T. J., \& Cregan, C. (2008). Known by the company we keep: Stigma-by-association effects in the workplace. Academy of Management Review, 33(1), 215-230.

Larson, J. E. \& Lane, F. J. (2006). A review of mental illness courtesy stigma for rehabilitation educators. Rehabilitation Education, 20(4), 247-252.

Letourneau, E. J., Levenson, J. S., Bandyopadhyay, D., Sinha, D., \& Armstrong, K. S. (2010). Effects of south Carolina's sex offender registration and notification policy on adult recidivism. Criminal Justice Policy Review, 21(4), 435-458.

Levenson, J. S., \& Cotter, L. P. (2005). The effect of Megan's law on sex offender reintegration. Journal of Contemporary Criminal Justice, 21, 49-66.

Levenson, J. \& Tewksbury, R. (2009). Collateral damage: Family members of registered sex offenders. American Journal of Criminal Justice, 34, 54-68.

Lichtenstein, B., Sturdevant, M. S., \& Mujumdar, A. (2010). Psychosocial stressors among HIV-affected families: Implications for social work practice. Journal of HIVIAIDS and Social Services, 9, 130-152.

Marsh, S. C., Russell, K. N., \& Evans, W. P. (2021). Trickle down registration: Exploring the lived experiences of partners of persons registered as a sexual offender. Health Communication, 1-7. 
Melendez, M. S., Lichtenstein, B., \& Dolliver, M. J. (2016). Mothers of mass murderers: Exploring public blame for the mother of school shooters through an application of courtesy stigma to the Columbine and Newtown tragedies. Deviant Behavior, 37(5), 525535.

Prescott, J. J. (2012). Do sex offender registries make us less safe? Crime \& Law Enforcement, 35(2), 48-55.

Pryor, J. B., Reeder, G. D., \& Monroe, A. E. (2012). The infection of bad company: Stigma by association. Journal of Personality and Social psychology, 102(2), 224-241.

Robbers, M. L. P. (2009). Lifers on the Outside: Sex Offenders and Disintegrative Shaming. International Journal of Offender Therapy and Comparative Criminology, 53(1).

Robertiello, G. \& Terry, K. J. (2007). Can we profile sex offenders? A review of sex offender typologies. Aggression and Violent Behavior, 12, 508-518.

Russell, K. N. (2020). Courtesy stigma: Examining the collateral consequences of sexual offenses and subsequent policy on partners of sexual offenders. (Publication No. 28029375) [Doctoral dissertation]. University of Nevada, Reno, ProQuest Dissertations Publishing.

Sample, L. L., \& Bray, T. M. (2006). Are sex offenders different? An examination of rearrest patterns. Criminal Justice Policy Review, 17(1), 83-102.

Socia, K. M. (2012). The efficacy of county-level sex offender residence restrictions in New York. Crime and Delinquency, 58(4), 612-642.

Tewksbury, R. (2005). Collateral Consequences of Sex Offender Registration. Journal of Contemporary Criminal Justice, 21(1), 67-81.

Tewksbury, R., \& Lees, M. (2006). Perceptions of sex offender registration: Collateral consequences and community experiences. Sociological Spectrum, 26, 309-334.

Tuckett, A. G. (2005). Applying thematic analysis theory to practice: A researcher's experience. Contemporary Nurse: A Journal for the Australian Nursing Profession, 19(12), 75-87. 
Vasquez, B. E., Maddan, S., \& Walker, J. T. (2008). The influence of sex offender registration and notification laws in the United States: A time-series analysis. Crime \& Delinquency, 54(2), 175-192.

Wright, R. G. (2008). From Wetterling to Walsh: The growth of federalization in sex offender policy. Federal Sentencing Reporter, 21, 124-132.

Zgoba, K. M., \& Mitchell, M. M. (2021). The effectiveness of sex offender registration and notification: A meta-analysis of 25 years of findings. Journal of Experimental Criminology.

Zevitz, R. G. (2006). Sex offender community notification: Its role in recidivism and offender reintegration. Criminal Justice Studies, 19(2), 193-208.

\section{Contributors}

Kristan N. Russell is an Assistant Professor of Justice Studies in the College of Juvenile Justice and a Research Scientist in the Texas Juvenile Crime Prevention Center at Prairie View A\&M University. Her research interests include sexual offending and related policy, stigma, juvenile justice, and perceptions of individuals convicted for sexual offenses.

Katie M. Snider is a doctoral candidate in the Interdisciplinary Social Psychology Ph.D. Program at the University of Nevada, Reno. Her research focuses on the experiences of offenders and their families interacting with justice institutions including juvenile justice systems and policy, specialty and trauma-responsive courts, and jail diversion programs and policies.

William P. Evans is a Professor of Education and Human Development, and Extension Specialist for Evaluation and Youth Development at the University of Nevada, Reno. His research interests include resiliency modeling, coping, evaluation, and youth development.

Shawn C. Marsh is an Associate Professor of Judicial Studies, Social Psychology, and Communication Studies and Director of Judicial Studies at the University of Nevada, Reno. His research interests include bias and decision-making, trauma-responsive justice, and juvenile justice. 


\section{Acknowledgment}

This work was supported by the Society for the Psychological Study of Social Issues (SPSSI) under the Grant-in-Aid and with matching funds from the Graduate School of the University of Nevada, Reno. 